\begin{abstract}
Title of thesis:

EXPOSURE OF CHILDREN TO DEET AND OTHERTOPICALLY APPLIED REPELLENTS

Kalapurakkal Sunil Menon, Master of Public Health, 2005

Thesis directed by:

Dr. Glenn R. Schiraldi, Ph.D.

Department of Public and Community Health.
\end{abstract}

Use of topical repellents on children is common. Anecdotal reports suggest repellents may be applied inappropriately, but no studies characterizing the actual usage patterns and exposure of children have been reported.

In summer 2002, a cross-sectional survey on the use patterns of repellents on children and possible associated effects was conducted in Maryland campgrounds. Information requested included products used, details of applications, post-application practices, and parents' decisionmaking process.

The study yielded 301 respondents. Deet was the most commonly used active ingredient $(83.4 \%)$; aerosols were the most common formulation $(42.5 \%)$. Over a third of subjects $(38.9 \%)$ treated their children's clothing as well as their skin. Over half of the children did not remove the repellent before going to bed. More than a third of parents failed to read or follow label directions.

This study provides documentation of practices leading to undesirable exposure. Educational outreach to change parents' usage patterns is required. 


\title{
EXPOSURE OF CHILDREN TO DEET AND OTHER TOPICALLY APPLIED INSECT REPELLENTS
}

\author{
by \\ Kalapurakkal Sunil Menon \\ Thesis submitted to the Faculty of the Graduate School of the \\ University of Maryland, College Park in partial fulfillment \\ of the requirements for the degree of \\ Master of Public Health \\ 2005
}

Advisory Committee:

Dr. Glenn R. Schiraldi, Ph.D (Chair)

Dr. Amy E. Brown, Ph.D

Dr. Sharon M. Desmond, Ph.D 
CCopyright by

Kalapurakkal Sunil Menon

2005 


\section{ACKNOWLEDGEMENTS}

I sincerely thank Dr. Glenn Schiraldi, Ph. D, for his tremendous help with this research from the outset to the finish. I thank Dr. Amy E. Brown, Ph.D, for her guidance, direction and perseverance and help with the research project, without which this work would not have been possible. I thank Dr. Sharon Desmond, Ph.D, for her help all throughout my MPH years. I express my gratitude for the park managers and rangers of the various state parks of Maryland, who have helped me in collection of the data. I thank all my teachers, friends and family for their good words, help and prayers without which I would not be where I am in life.

Kalapurakkal Sunil Menon. 


\section{TABLE OF CONTENTS}

\section{Abstract}

Acknowledgements...................................................................ii

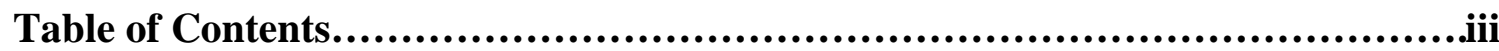

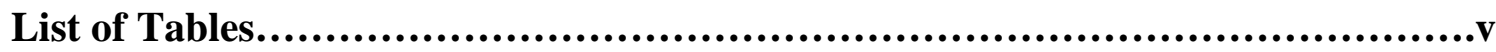

List of Figures.........................................................................

\section{Chapter One - Introduction}

Problem statement..........................................................

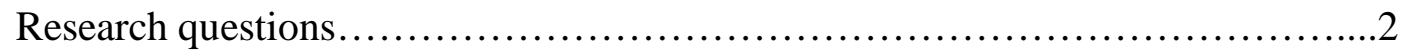

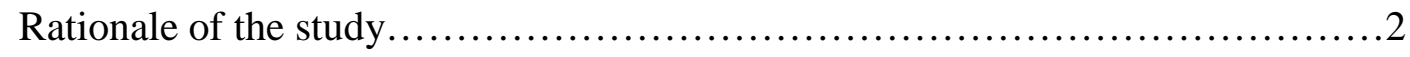

Definition of terms...................................................... 4

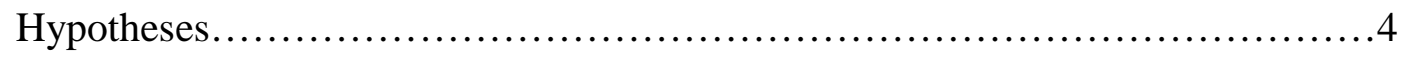

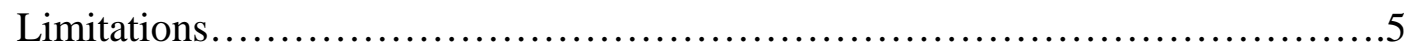

Chapter Two - Literature review....................................................6

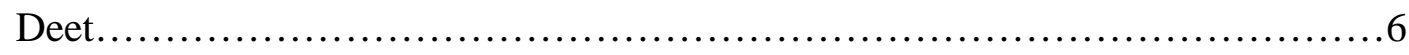

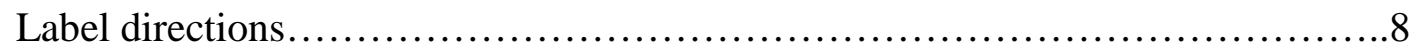

EPA recommendations....................................................

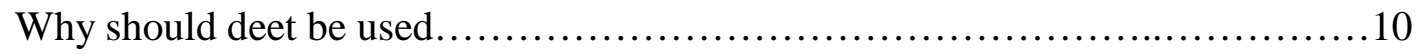

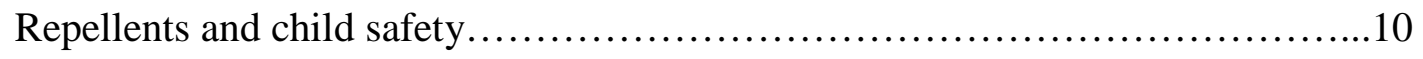

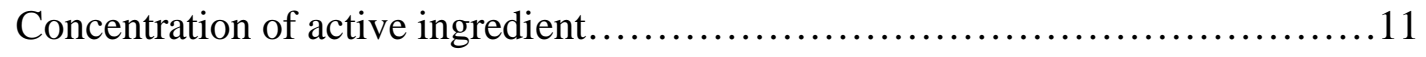

Chapter Three - Methods................................................................12

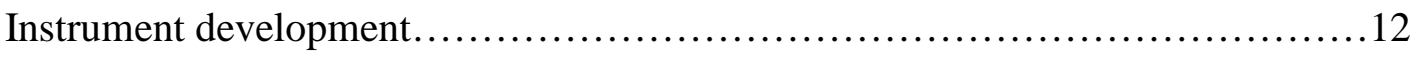


Pilot study........................................................ 13

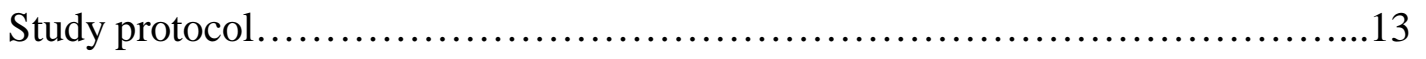

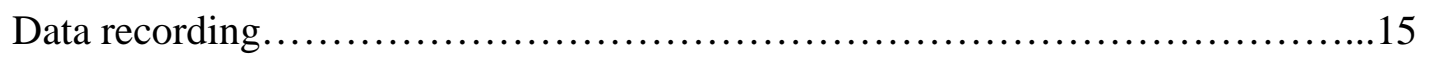

Data analysis........................................................ 15

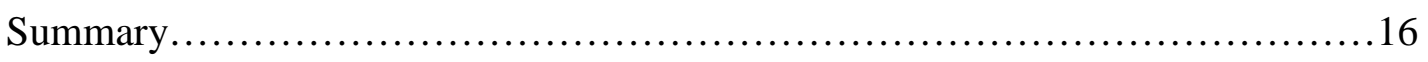

Chapter Four: Results.................................................................17

Characterization of the study population................................. 17

Product information................................................... 17

Use patterns......................................................... 18

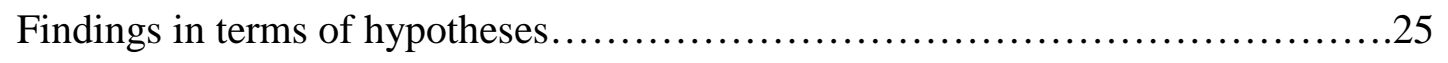

Chapter Five: Conclusions and recommendations.................................26

Future research questions............................................. 30

Appendices...................................................................................32

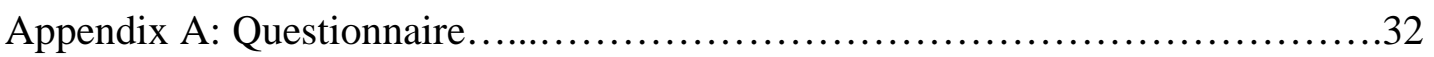

Appendix B: Letter to campground manager..............................42

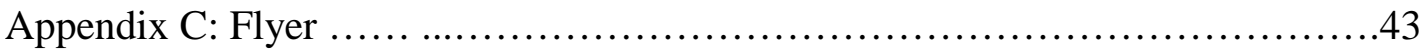

Appendix D: Questionnaire with answers................................44

Appendix E: Informed consent and/or permission form.....................54

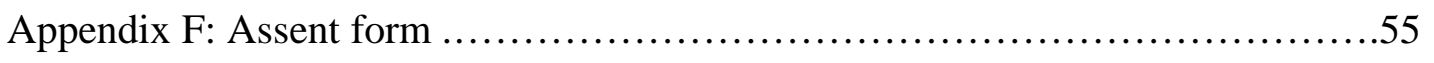

References...............................................................................65 


\section{LIST OF TABLES}

Table 1: Symptoms of overexposure to pesticides applied topically to control insects and other

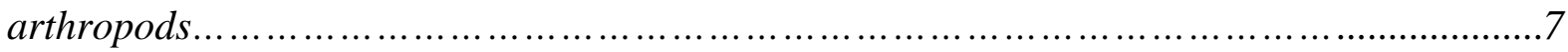

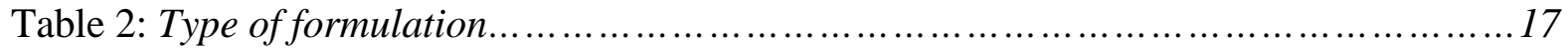

Table 3: Identity of person applying the repellent.............................................17

Table 4: Relationship between the time between applications, number of subjects and number of

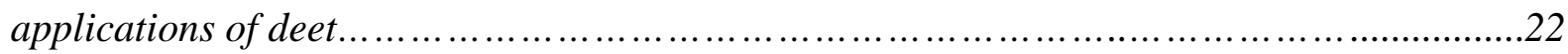

Table 5: Choice of repellent...................................................................24 


\section{LIST OF FIGURES}

Figure 1: Repellents applied to children in Maryland campgrounds, Summer 2002..........18 Figure 2: Frequency of repeated applications of deet without washing off in between, summer $2002(n=73)$

Figure 3: Areas of children's bodies treated with repellent in Maryland campgrounds, summer

2002 . 


\section{CHAPTER ONE}

\section{INTRODUCTION}

\section{$\underline{\text { Problem statement }}$}

Insect repellents are fairly commonly used in the general population of North America (Fradin \& Day, 2000). Even though insect repellents help in warding off disease causing insect vectors, they may potentially cause adverse reactions, which may be acute or chronic (Edwards \& Johnson, 1987; Hayes \& Laws, 1991). Anecdotal reports suggest that parents may apply insect repellent products more frequently and for a longer duration than the labels allow. Hence, there is a need to document the exposure profiles of children to these chemicals. Because acute, chronic, and allergic effects have been suggested to be associated with the application of some of these products (Edwards \& Johnson, 1987; Hampers, Okar \& Leikin, 1999; Lipscomb, Cramer \& Lefkin, 1992; Osimitz \& Murphy, 1997; Petrucci \& Sardini, 2000; Qiu, Jun \& McCall, 1998; Roland, Jan \& Rigg, 1985; Sudakin \& Trevathan, 2003), the incidence of such symptoms should also be studied in children who are exposed. However, it is to be noted that the documented toxic effects due to insect repellents have all either been on lower animals or when the route of exposure was oral ingestion. Since there is no literature about the exposure profile of the insect repellents and adverse effects, there is a need to provide a detailed profile of exposure of children to the insect repellents, and analyze reported symptoms in the study population, if any. The purpose of the study was, first to provide a detailed profile of exposure of children to the insect repellents, and secondarily to analyze any reported symptoms in the study population. 


\section{$\underline{\text { Research questions: }}$}

1. What are the insect repellents applied to the children?

2. Do parents/care givers follow label directions as required by the Environmental Protection Agency?

3. Are significant acute adverse reactions associated with improper application of insect repellents?

\section{Rationale of the study:}

Pesticides are used to produce a plentiful food supply, maintain buildings, achieve aesthetically pleasing surroundings, and to control pests which constitute a nuisance or public health threat. Certain pesticides are designed to be applied to the skin to control pests such as lice and scabies, or to repel ticks, mosquitoes, and biting flies. In addition to reducing annoyance from biting and sucking pests, repellents reduce the potential for diseases vectored by ticks and mosquitoes.

Although pesticides can provide great benefits, they have a potential to cause adverse health effects, especially when used improperly. Such effects can occur to all, but children are physiologically and developmentally at increased risk to the toxic effects. There have been reports of side effects like rashes and skin reactions to deet. Higher concentrations of deet have been associated with seizures. Deet exposure via routes other than topical (eg: ingestion) have been associated with fatalities.

Epidemiological studies have suggested that children exposed to certain pesticides have an increased risk of childhood cancers, possible neurobehavioral effects, congenital 
malformations and other health effects (Briassoulis, Narlioglou, \& Hatzis, 2001). Due to the immature nature of their immune system, bigger surface area to body weight ratio, higher metabolic rate, different diet patterns and activities, different exposure profiles and hormonal changes at puberty, children incur more risk than adults (Briassoulis et al, 2001). To minimize these potential risks, directions for safe use of pesticides are required as part of every insect repellent label registered for use in the United States (U.S). The U. S. Environmental Protection Agency (EPA) evaluates pesticides to make sure that they would not cause undue harm when used as directed on the label. Therefore it is extremely important that pesticides be used as directed on the label. Label statements are specific and include site of application, rate or concentration at which to apply, precautions necessary for proper use, first aid procedures, and other important information (Brown, 1999).

The deer tick is known to transmit Lyme disease, and several species of mosquitoes have been shown to be capable of transmitting West Nile Virus, an emerging problem that began in the U.S. along the eastern seaboard and has now penetrated a large part of the country. Because of the chronic and potentially serious nature of the symptoms associated with these diseases, even though the risk of contracting the disease may be low, it is thought that the use of insect repellents is on the increase. Although products may contain one or more of several active ingredients, deet ( $\mathrm{N}, \mathrm{N}$,-Diethyl-meta-toluamide), is the most commonly used repellent in the U.S. There are several deet-free or "natural" insect repellents in the market and this may reflect a popular concern about the safety of deet.

In 1998, the EPA, which regulates pesticides in the U.S., called for new directions on deet products: "Do not use on hands or near eyes and mouth of young children. Do not use under 
clothing. Avoid over-application of this product. After returning indoors, wash treated skin with soap and water and wash treated clothing" (Craigmill, 1998).

Use of repellents on children is common and, for achieving good control of these nuisance and disease-carrying arthropods, sometimes necessary. But there is a need to find out if the application of repellents on children is as required by the EPA or not. This would help the EPA decide if the safety practices required by the EPA are enough or not.

There have been no studies characterizing the exposure patterns of children to the insect repellents and this study attempts to fill this void and thus provide the EPA with feedback on whether pesticide regulation processes are having the desired effect or if there is a need to change the prescribed pesticide safety practices.

\section{$\underline{\text { Definition of terms: }}$}

Active Ingredients: This is the ingredient/chemical that has the desired effect of warding off mosquitoes and ticks.

Washing off: Removal of repellent in any manner with water, like bathing, swimming, washing etc.

\section{Hypotheses:}

1. The active ingredient of most insect repellents used will be deet.

2. Most parents/ adult care givers are not using insect repellents in the manner advised by the EPA.

3. Improper application of deet-containing repellents w1l be associated with acute adverse 
symptoms in children.

\section{Limitations:}

There are other conditions which can present with symptoms similar to those that can be expected from overexposure to the products investigated in this study. Conditions such as

allergic diatheses, allergic manifestations from environmental exposure at the campground, Flu or other low grade illnesses and adverse reactions to medications can present with symptoms indistinguishable from low grade pesticide poisoning. The study was not designed to detect any chronic adverse reactions.

Selection bias can occur due to the random response as parents who are generally more concerned about their children's health might be more likely to respond and they might also be more likely to recall a possible adverse effect. Such individuals may also be more prone to incorrectly ascribe any skin reaction to that caused by application of the repellent.

The study has the limitations of a self report survey. Parents/ caregivers may not have been entirely truthful about their use of repellents on children. Because the study did not involve physical examination of the children, the actual incidence of the side effects may have been underreported. 


\section{CHAPTER TWO}

\section{LITERATURE REVIEW}

$\underline{\text { Deet: }}$

Deet (chemical name, N, N-diethyl-meta-toluamide) is the active ingredient in many insect repellent products. It is used to repel biting pests such as mosquitoes and ticks, including ticks that may carry Lyme disease causing agents. Every year, approximately one-third of the U.S. population is expected to use deet (EPA, 1998). Products containing deet currently are available to the public in a variety of forms (liquids, lotions, sprays, and impregnated materials like wrist bands). Formulations registered for direct application to human skin contain from 4 to $100 \%$ deet. Except for a few veterinary uses, deet is registered for use by consumers, and it is not used on food (United States Environmental Protection Agency (EPA, 1998).

Active ingredients and concentrations of repellents vary. The repellents contain chemicals ranging from deet (diethyl m-toluamide) to natural agents like soybean oil (eg: Blocker Insect Repellent), geranium oil, citronella, cedarwood oil (eg: Bug Block) etc. Table 1 represents the repellent ingredients, possible adverse effects, and target pests.

Deet is designed for direct application to human skin to repel insects, rather than kill them. After it was developed by the U.S. Army in 1946, deet was registered for use by the general public in 1957. Approximately 230 products containing deet are currently registered with EPA by about 70 different companies (EPA 1998). In 1998, EPA called for new directions on deet products (Craigmill, 1998). 
$\underline{\text { Table } 1}$

Symptoms of overexposure to pesticides applied topically to control insects and other arthropods.

\begin{tabular}{lll}
\hline Repellent & Target pest & $\begin{array}{l}\text { Symptoms associated with acute } \\
\text { toxicity or allergic reactions (Fradin, } \\
\text { 1998, Reigart \& Roberts, 1999) }\end{array}$ \\
\hline $\begin{array}{l}\text { Deet-containing } \\
\text { repellents }\end{array}$ & $\begin{array}{l}\text { Mosquitoes } \\
\text { Ticks }\end{array}$ & $\begin{array}{l}\text { Headache, lethargy, confusion, } \\
\text { behavioral changes, wheals. } \\
\text { With very high doses: encephalopathy, } \\
\text { seizures }\end{array}$ \\
$\begin{array}{l}\text { Skin-so-soft } \\
\text { (moisturizer/repellent) }\end{array}$ & Mosquitoes & Nil reported \\
Citronella & Mosquitoes & Nil reported \\
Soyabean oil & Mosquitoes & Nil reported \\
Geranium oil & Mosquitoes & Nil reported \\
Coconut oil & Mosquitoes & Nil reported \\
Permethrin & $\begin{array}{l}\text { Ticks, mosquitoes } \\
\text { (To be applied to clothing } \\
\text { only, not to skin) }\end{array}$ & $\begin{array}{l}\text { Itching, burning at site of } \\
\text { application; headache. High } \\
\text { doses: dizziness, salivation, fatigue, } \\
\text { vomiting, diarrhea, muscle fasciculations }\end{array}$ \\
& &
\end{tabular}

The EPA recently issued a Reregistration Eligibility Decision (RED) for the chemical deet. A comprehensive re- assessment of deet was done by EPA and thereafter concluded that, as long as consumers follow label directions and take proper precautions, insect repellents containing deet do not present a health concern. Human exposure is usually of short duration. Based on extensive toxicity testing, the Agency believed that the normal use of deet wouldhot present a health concern to the general population (EPA, 1998).

Health authorities recommend that young children not be permitted to apply repellents to 
them, and that faces not be treated directly (American Academy of Pediatrics 2000; Health Canada 2003; EPA 1998; Lowe 2000). Authorities and pesticide labels recommend avoiding over application of deet (Health Canada, 2003; EPA, 1998; Lowe, 2000; Reigart \& Roberts, 1999).

It is recommended that only exposed skin be treated with repellents (American Academy of Pediatrics, 2000). As long clothing alone is considered protective against biting insects, use of a repellent under the clothing would represent an unnecessary exposure, and use of the repellent under clothing has been shown to increase absorption of deet (Riviere, Baynes, Brooks, Yeatts, \& Monteiro-Riviere, 2003).

In an assessment of deet poisoning incidents reported to Poison Control Centers, eye contact was associated with the highest rate of symptoms (Bell, Veltri, \& Page, 2002). Treatment of palms of the hands should be avoided, as this also can lead to contamination of the face, eyes, and mouth through transference of the product.

\section{Label directions:}

The EPA, after extensively testing a product, issues the label directions which are required to be pasted on the container. The label also contains a company telephone number or toll-free number on all product labels for consumers to call for additional product information and to report incidents. Possible adverse reactions are listed, as is the first aid in case of an adverse reaction (EPA, 1998).

The following is a typical example of label statements as used on insect repellents (EPA, 1998). Consumers can reduce their own risks when using deet by reading and following the 
products' labels.

"Read and follow all directions and precautions on this product label.

- Do not apply over cuts, wounds, or irritated skin.

- Do not apply to hands or near eyes and mouth of young children.

- Do not allow young children to apply this product.

- Use just enough repellent to cover exposed skin and/or clothing.

- Do not use under clothing.

- Avoid over-application of this product.

- After returning indoors, wash treated skin with soap and water.

- Wash treated clothing before wearing again.

- Use of this product may cause skin reactions in rare cases.

The following additional statements will appear on the labels of all aerosol and pump spray formulation labels:

- Do not spray in enclosed areas.

- To apply to face, spray on hands first and then rub on face. Do not spray directly onto face" (EPA, 1998).

The EPA (EPA, 1998) recommends the following precautions when using an insect repellent or pesticide. It clearly states the importance of following directions on the label:

- "Check the container to ensure that the product bears an EPA approved label and 
registration number. Never use a product that has not been approved for use by the EPA.

- Read the entire label before using a pesticide. Even if you have used it before, read the label again—don't trust your memory.

- Follow directions carefully, use only the amount directed, at the time and under the conditions specified, and for the purpose listed. For example, if you need a tick repellent, make sure that the product label lists this use. If ticks are not listed, the product may not be formulated for this use.

- Store pesticides away from children's reach, in a locked utility cabinet or garden shed"

Why should deet be used?

Deet is a powerful insect repellent and repels potentially disease-carrying mosquitoes and ticks. Nearly 10,000 reports of Lyme disease (transmitted by deer ticks) and 1,000 reports of encephalitis (transmitted by mosquitoes) are reported to the Centers for Disease Control (CDC) annually (EPA, 1998). Both of these diseases can cause serious health problems or even death in the case of encephalitis. Studies suggest that deet repels ticks for about three to eight hours, depending on the percentage of the active ingredient in the product (EPA, 1998).

\section{Repellents and Child Safety:}

The EPA is no longer allowing child safety claims on product labels. These claims currently appear on certain products containing a deet concentration of $15 \%$ or less. Canada has abolished the use of insect repellents containing more than $30 \%$ deet. The scientific data on deet 
does not support product label claims of child safety based on the percentage of active ingredient.

\section{Concentration of Active Ingredient:}

An extra-strength product may not necessarily provide extra protection (EPA, 1998). Although it may need to be applied more often, a lower-strength product lessens the chances of an adverse reaction to the chemical. Hence it has recently been suggested that products with lower concentration of active ingredients be used in the market (EPA, 1998). 


\section{CHAPTER THREE}

\section{METHODS}

\section{$\underline{\text { Introduction }}$}

The study involved a survey of use of insect repellents applied to children at various state campgrounds in Maryland. It was a cross-sectional survey. A questionnaire (Appendix A) elicited information about exposure profiles and possible associated health effects. State campgrounds in Maryland were contacted (Appendix B) and permission was sought to contact the campers there. A flyer (Appendix C) was sent to the campgrounds which agreed to participate as venues of the survey for general information and for information of the potential subjects.

\section{Instrument development:}

The questionnaire was a new instrument developed by Dr. Amy Brown. The reason for developing a new instrument was that even though the literature was searched extensively for established instruments none were found. Also, discussion with experts in the field failed to bring up an instrument of the type required for the survey. The aim while developing the instrument was to be able to complete the survey in 20 minutes to be within the attention span of the subject. The questions were framed with this in mind and the questions were framed to find out who, what, where and how the insect repellents were used. 


\section{Pilot Study:}

The survey instrument was fine-tuned before the actual survey by doing a pilot survey on campers at one of the campgrounds selected for the study. The pilot study was conducted on 10 camping families/groups and the questionnaire was modified thereafter to include some of the questions and concerns that they had had.

\section{Study protocol:}

The study campgrounds were chosen from the Northern, Southern, Western and Eastern shore of Maryland. A good mix of campgrounds, ie., from seashore to mountainous areas was chosen. In all there were eight campgrounds. The chosen ones were at driving distance from the University of Maryland and they all had mosquito problems during summer. The campgrounds visited were Big Run State Park, New Germany State Park, Cedarville State Forest, Assateague State Park, Elk Neck State Park, Cunningham Falls State Park, Janes' Island State Park and Greenbrier State Park. The researchers had a target of 250-400 subjects at the start of the study. The researchers felt that this number would be adequate for drawing conclusions from the study.

The campgrounds were visited mostly during the evenings, which was the time when family members used to regroup for dinner. The survey was administered during the months of May-August 2002 (four months). Exact timing of visits was scheduled in relation to the most likely periods of pest outbreaks in the campground, based on local knowledge of the camp operators. This may vary from year to year. The study targeted children 18 years of age or younger.

The researcher approached parents or adult care givers, introduced him, politely 
explained the purpose of the study, and requested their cooperation. If they agreed to participate, then the questions were read out to the parent and the answers were recorded by the researcher. If a child applied the insecticide himself/herself, permission was requested from the parents to interview the child. As needed in each case, informed consent and/or permission was obtained from the parents (Appendix E) and assent (Appendix F) from children younger than 18 years of age. No identifying information was asked on the form, and confidentiality of the data was maintained.

To maximize accuracy of the information provided concerning the product used, respondents were asked to show the product to the researcher, who then took note of the active ingredient(s) and concentration. In cases where the product was not available or the respondent refused to provide it, photographs of commonly available insect repellents were presented to the respondents to aid in recall.

In families with more than one child, the parent was asked to provide information concerning the youngest child treated. To reduce the potential for recall errors, the survey questions targeted the use patterns during the single most recent application of repellents. The use patterns of the repellents including the number of applications, duration of each application, body parts treated with repellents each time, and care of clothes and body after application were queried. The respondents were asked about their usual use pattern of repellents, if different from the last day on which a repellent was used. Subjects were also asked whether their child had exhibited any of a series of symptoms or conditions, some of which are theorized to be associated with topical application of these products, and others which are not expected to have any association. 
Parents who responded that they had not use repellents on their child during the campground stay were asked whether the reason was lack of efficacy or previous adverse reaction. They then were asked to answer the questions concerning health effects of the child on a particular day of their visit. This helped provide an estimated baseline of health effects that may occur without the use of repellents in the same setting.

After the questionnaire had been completed, the parent/guardian was given a card with information about the University of Maryland Pesticide Education and Assessment Program website, where information about the proper method of application of repellents is available.

The protocol of the study was submitted to the Institutional Review Board of the University of Maryland which approved the study.

\section{Data Recording:}

The data so collected was entered into a Microsoft Excel master chart. Separate columns were made for each question that was asked and results tabulated.

\section{Data Analysis:}

The data were analyzed descriptively, with range, mean, percentage and mode. The first hypothesis was analyzed by finding the percentage of parents/ caregivers who applied deet.

The second hypothesis was analyzed by range, mean, percentage and mode. The relationship between male caregiver applying to palms and faces of children and female caregiver applying to palms and faces of children was statistically assessed using the Chi-Square test. 
The third hypothesis could not be analyzed due to inadequate number of adverse effects noted in the study.

Summary:

The cross-sectional face to face survey on use patterns of topically applied repellents and possible adverse reactions was conducted after developing and validating the instrument (questionnaire). The survey was conducted in various Maryland state campgrounds during the summer of 2002. 


\section{CHAPTER FOUR}

\section{RESULTS}

\section{Characterization of the Study Population}

A total of 301 parents or care-givers completed the survey. Altogether 400-500 potential subjects were approached and the response rate was approximately 70 percent. All of these subjects had used a repellent on their child within their current campground stay. Unless otherwise stated, all percentages are calculated on the basis of the 301 subjects. There were 104 respondents from Assateague State Park, three from Big Run State Park, eight from Cedarville State Forest, 100 respondents from Cunningham Falls State Park, 16 from Elk Neck State Park, 61 from Greenbrier State Park, three from Janes' Island State Park and seven from New Germany State Park.

Age of children in the study ranged from three months to18 years, and average age was 6.7 (Standard deviation, SD = 3.6 years) years. There were 159 male and 142 female children. Average age of the male children was $7.1(\mathrm{SD}=3.7)$ years, and that of female children was 6.3 $(\mathrm{SD}=3.3)$ years.

\section{$\underline{\text { Product Information }}$}

On most occasions $(90.0 \%)$, the product used was shown to the researcher. On $21(7.0 \%)$ occasions, subjects identified products from photographs. The subject recalled product name and information on eight $(2.7 \%)$ occasions and only on one $(0.3 \%)$ occasion was the subject unable to identify the product through any of these methods. As hypothesized, deet was the active 
ingredient used by most families (83.4\%) (Figure 1). Concentration of deet as active ingredient in products used ranged from $4.75 \%$ to $95.0 \%$. There was no association between concentration of deet and age of child treated. Only thirteen subjects (4.3\%) had changed their repellent product within the past year from the date of the survey.

Aerosols were used most commonly (Table 2), followed by pump sprays and lotions. Two subjects used wristbands impregnated with repellent, and one subject used repellent towelettes. Ten percent used products containing both repellent and sunscreen.

Table 2: Type of formulation

\begin{tabular}{ll}
\hline Type of formulation & Percent of parents \\
\hline Aerosols & 42.5 \\
Pump sprays & 34.9 \\
Lotion & 21.6 \\
Wristbands & 0.66 \\
Towelettes & 0.33 \\
\hline
\end{tabular}

Most parents/ caregivers found the product they use to be effective. 276 respondents $(91.7 \%)$ found the product effective, $13(4.3 \%)$ found the product ineffective and $12(4.0 \%)$ were unsure.

\section{$\underline{\text { Use Patterns }}$}

Identity of the person applying repellent to the child:

Table 3: Identity of person applying the repellent

\begin{tabular}{ll}
\hline Person applying the & Frequency \\
Repellent & \\
\hline Mother & $63.5 \%$ \\
Father & $20.9 \%$ \\
Other primary caregiver & $4.3 \%$ \\
Child & $3.7 \%$ \\
Combination & $7.4 \%$ \\
\hline
\end{tabular}




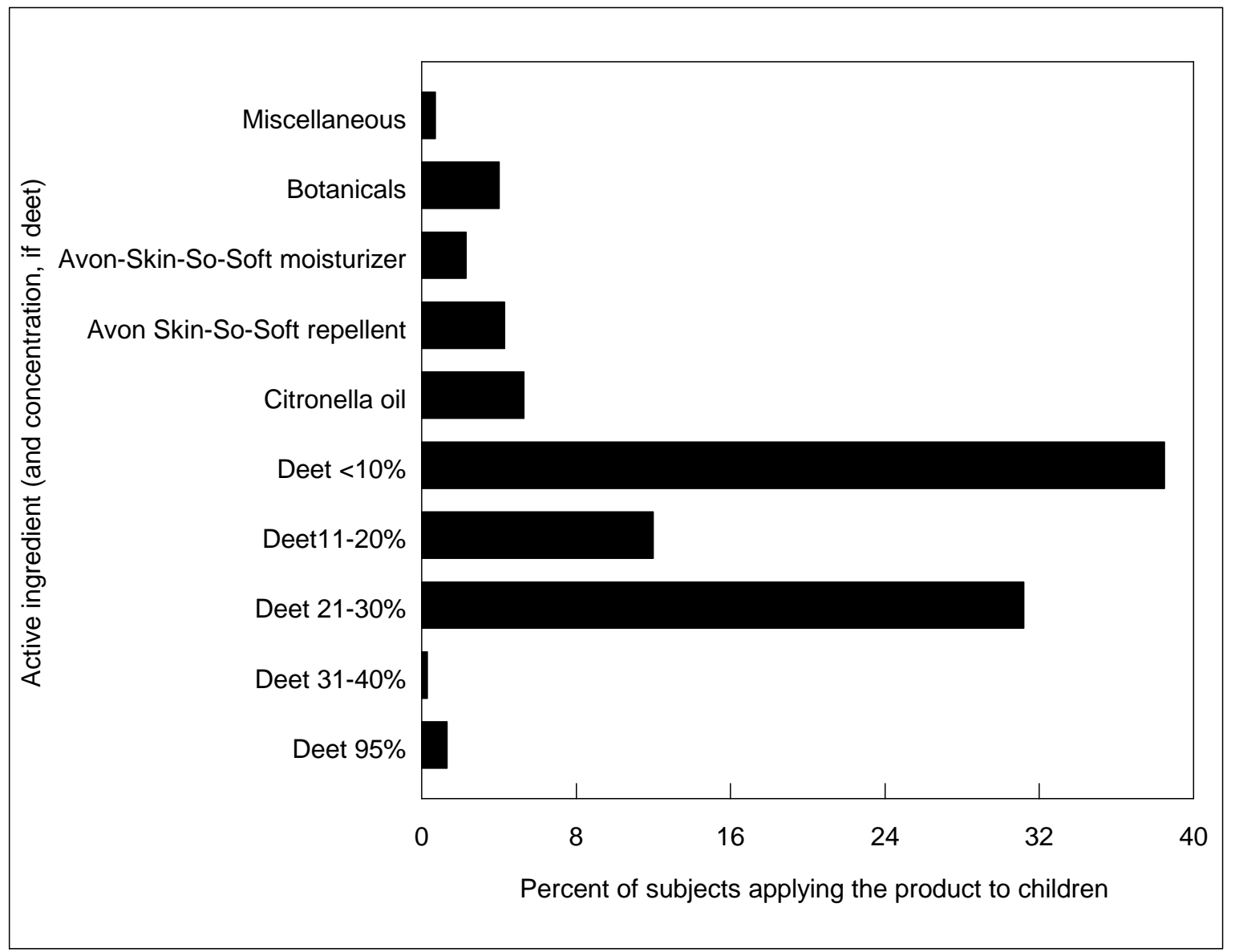

Figure 1: Repellents applied to children in Maryland campgrounds, Summer 2002

Repellent was applied by the mother in most cases, the father in one fifth of the cases and in some cases by the other primary care giver or child (Table 3). Fathers were more likely than mothers to treat the palms $(p=0.01)$ and to directly treat the faces of the children $(p=0.03)$. 
Eleven children younger than 14 (average age $=10.5$ years, $\mathrm{SD}=4.3$ ) applied the repellent to themselves; ten of these children used deet.

While residence at campgrounds lasted from one day to more than one week (maximum in the survey was 25 days), most respondents (65.8\%) spent two or three days at the campground, mostly on weekends. This is reflected in the number of days on which repellents were applied, which ranged from one through 14 , with $46.5 \%$ of subjects applying repellent to the child on one day only, and another $29.9 \%$ applying repellent on two days.

Of the 301 subjects, $241(80.0 \%)$ had applied repellent on the day before the survey, 37 $(12.3 \%)$ two days prior to the survey, $11(3.7 \%)$ three days before the survey and 12 subjects $(4.0 \%)$ had last applied a repellent before that time interval.

Areas of the body treated: Arms, legs, and feet were the most frequently treated parts of the children's bodies (Figure 3). Of the roughly one-third (34.9\%) of parents who applied a repellent to their child's face, $54.3 \%$ applied it to their own hands first and then used their hands to treat the child's face, $32.4 \%$ applied it to the child's hands and the child then applied it to his/her own face, and $10.5 \%$ applied the repellent directly to the child's face, using an aerosol or pump formulation.

The clothes worn by the child after application of the repellent were predominantly shorts and tee shirts. Over a third of parents (38.9\%) purposely applied repellent (the same spray or aerosol used on the skin) to their child's clothes in addition to their skin. Three subjects (1.0\%) used repellent only on their child's clothes and not on the skin. 
Frequency of application: Over three-quarters of subjects (75.7\%) applied repellent only once during the day (63.7\%), or washed between applications (12.0\%), whereas the remaining $24.3 \%$ ( $n=73$ ) applied the repellent more than once without bathing, swimming, or washing off in between. Deet was used by $89.7 \%$ of those applying multiple times without washing off in some manner. Of those applying deet multiple times, $85.2 \%$ applied twice and $8.2 \%$ applied three times. The maximum number of applications of deet on one day without washing off between applications was six. Time between applications without washing off ranged from 15 minutes to 13 hours, with an average of 4.0 hours and a mode of 2.0 hours (Figure 3 ).

Out of the 73 subjects who had received deet application repeatedly, without washing off in between, 57 said that the reason was perceived need for more pest repellency while nine subjects said that the repellent was removed by other means, six wanted more sun protection as they were using a combination of repellent and sunscreen and one child was showing off.

In some cases, even though the number of subjects applying deet within a certain time interval was small, the frequency of applications made at that time interval was high. For example, eleven subjects applied deet two hours apart, but 24 applications were made by the 11 individuals (Table 4).

Example: The number of subjects applying deet one hour apart was seven, while the number of times the repellent was actually applied was 16 . So the child may have had deet applied to him/ her at $9 \mathrm{am}$ and again at $10 \mathrm{am}$. The same child may have had deet reapplied to $\mathrm{him} /$ her at say $1 \mathrm{pm}$ and again at $2 \mathrm{pm}$. So this child had had two occasions where deet had been applied to him one hour apart. Another child may have had deet applied to him one hour apart only once in a day and so on. So even though the number of children having deet applied to them 
one hour apart was only seven, the number of such paired applications was sixteen.

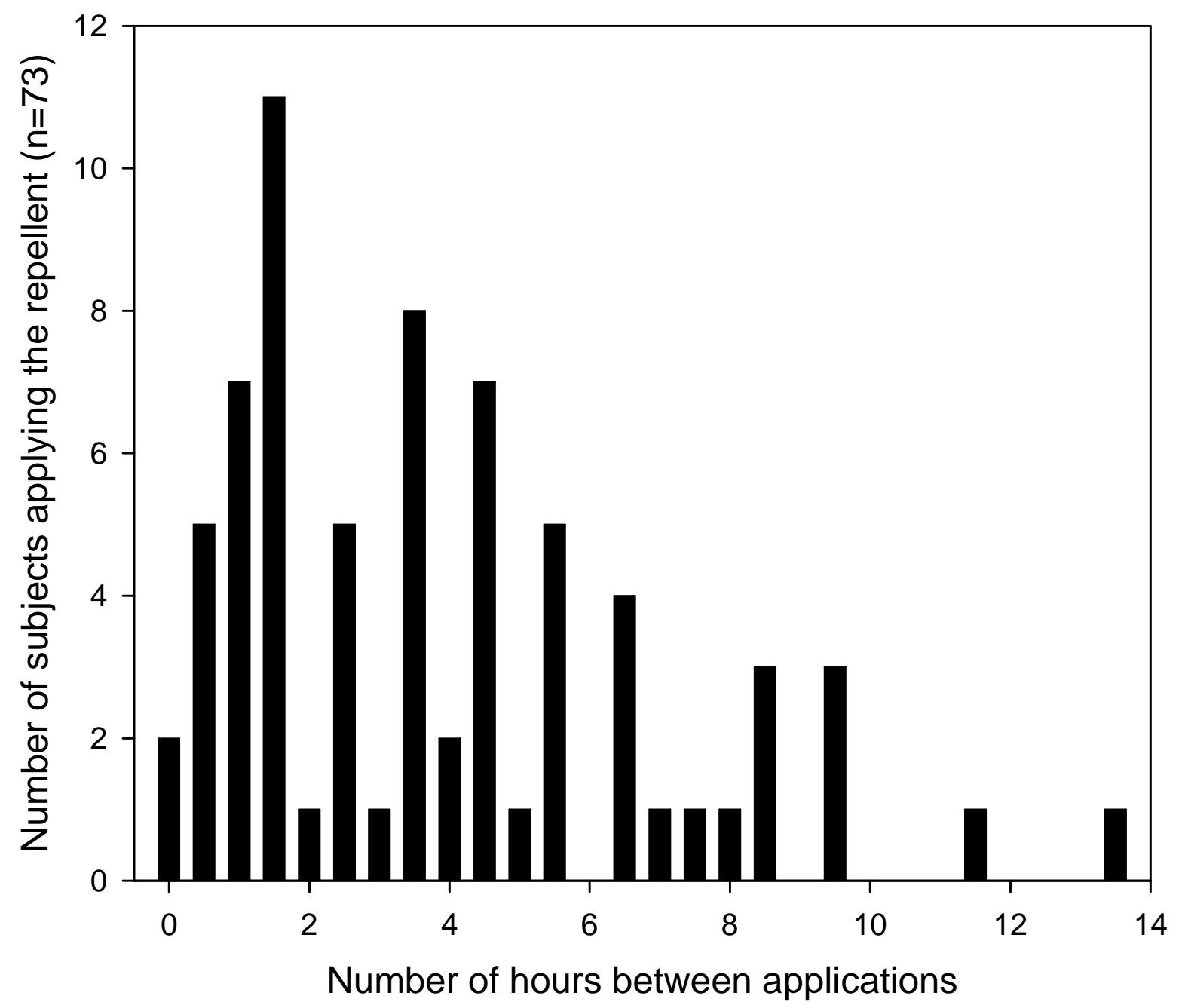

Figure 2: Frequency of repeated applications of deet without washing off in between, Summer $2002(n=73)$ 
Table 4: Relationship between the time between applications, number of subjects and number of applications of deet

\begin{tabular}{|c|c|c|}
\hline $\begin{array}{l}\text { Time between } \\
\text { applications of deet }\end{array}$ & $\begin{array}{l}\text { Number of subjects } \\
\text { applying deet }\end{array}$ & $\begin{array}{l}\text { Number of times the } \\
\text { subject applied deet }\end{array}$ \\
\hline 15 Minutes & 2 & 3 \\
\hline 30 Minutes & 5 & 8 \\
\hline 1 Hour & 7 & 16 \\
\hline 1.5 Hours & 3 & 3 \\
\hline 2 Hours & 11 & 24 \\
\hline 2.5 Hours & 1 & 1 \\
\hline 3 Hours & 5 & 5 \\
\hline 3.5 Hours & 1 & 2 \\
\hline 4 Hours & 8 & 8 \\
\hline 4.5 Hours & 2 & 2 \\
\hline 5 Hours & 7 & 7 \\
\hline 5.5 Hours & 1 & 1 \\
\hline 6 Hours & 5 & 5 \\
\hline 6.5 Hours & 0 & 0 \\
\hline 7 Hours & 4 & 4 \\
\hline 7.5 Hours & 1 & 1 \\
\hline 8 Hours & 1 & 1 \\
\hline 8.5 Hours & 1 & 1 \\
\hline 9 Hours & 3 & 4 \\
\hline 9.5 Hours & 0 & 0 \\
\hline 10 Hours & 3 & 3 \\
\hline 10.5 Hours & 0 & 0 \\
\hline 11 Hours & 0 & 0 \\
\hline 11.5 Hours & 1 & 1 \\
\hline 12 Hours & 0 & 0 \\
\hline 12.5 Hours & 0 & 0 \\
\hline 13 Hours & 1 & 1 \\
\hline
\end{tabular}




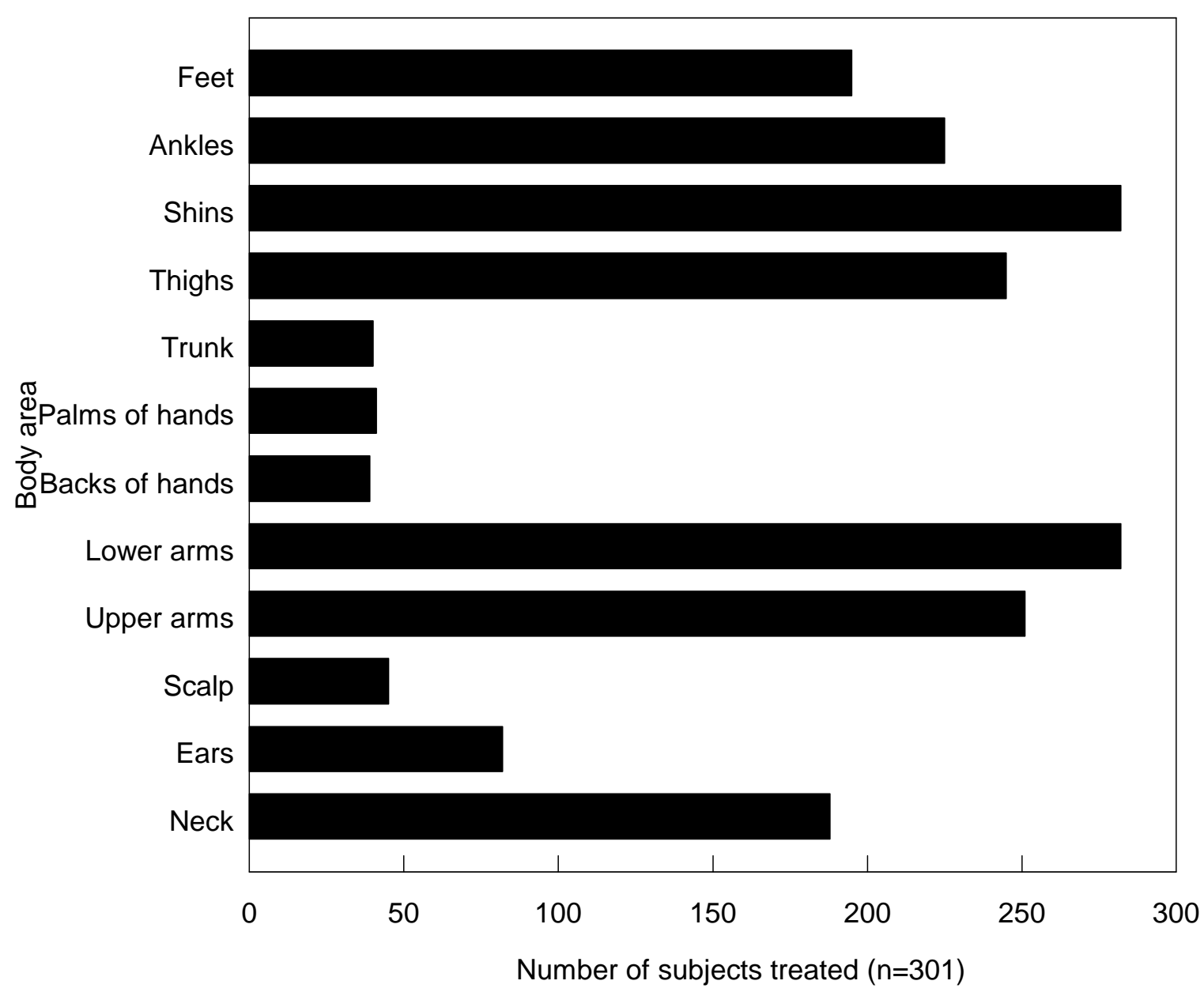

Figure 3: Areas of children's bodies treated with repellent in Maryland campgrounds, Summer 2002

Almost half (44.1\%) of the incidences of multiple application of deet without washing involved formulations of less than $10 \%$ deet. All of the remaining cases involved application of products in the range of $20-30 \%$ deet concentration, with the exception of a single subject (the grandfather) applying 95\% deet twice in four hours to a two-year old boy.

Duration of repellent contact with skin: Repellent contact hours $(\mathrm{RCH})$ was calculated from the time repellent was applied to the skin to the time it was removed through swimming, bathing, or 
otherwise washing it off. In the $55.1 \%$ of cases where the child went to bed without in some way washing off the repellent, $\mathrm{RCH}$ was calculated from the time of application to $10 \mathrm{AM}$ the following morning. For the 232 subjects applying repellent only once, average RCH was found to be 11.3 hours/person/camping day. Subjects applying formulations of $11 \%$ or more deet were no more likely than those using a concentration of less than or equal to $10 \%$ deet to wash the repellent off before bed.

\section{Decisions on Choice and Use of Products}

No single reason for choosing a particular repellent was obvious. Parents' reported choice of repellent was largely based on previous experience, price, advertisements and brand names and convenience and availability (Table 5).

Table 5: Choice of repellent

\begin{tabular}{ll}
\hline Reason for choosing repellent & Percent of parents \\
\hline Previous experience & 16.6 \\
Price & 15.3 \\
Advertisements and brand names & 13.6 \\
Convenience and availability & 13.6 \\
Recommendations from a trusted source & 7.0 \\
Advertisements for family/kids & 3.4 \\
Appearance of the container & 2.6 \\
Product aroma & 2.6 \\
Low deet concentration & 12.0 \\
High deet concentration & 4.3 \\
"Natural" products & 9.0 \\
\hline
\end{tabular}

In deciding how to use the product(s) they had chosen, 27 respondents $(9.0 \%)$ cited previous experience and $56(18.6 \%)$ cited "common sense.” Not every parent provided information on whether they read and followed label directions; therefore numbers on 
compliance cannot be accurately calculated. However, 105 (34.9\%) volunteered that they did not follow the directions on the label, while 93 (30.9\%) reported that they followed all directions on the label. Of the 105 subjects who volunteered that they did not follow label directions, 19 (18.1\%) had used a non-deet product while $86(81.9 \%)$ had used a deet containing product. Thirty-five subjects had increased or planned to increase their use of repellents due to concern about West Nile Virus (WNV) (65.7\%), Lyme Disease (11.4\%), or both (20.0\%).

\section{Findings in terms of hypotheses:}

The first hypothesis was confirmed; deet was the commonest insect repellent which was being used.

The second hypothesis was also confirmed. Parents/care givers were using insect repellents in methods that violated the guidelines of the EPA. A third of the parents volunteered that they do not read/follow label directions. A number of other caregivers applied repellents repeatedly without washing off in between or left them on for longer than desired/overnight or applied it manners not in concordance with EPA guidelines.

The third hypothesis, however, was negated. Out of the 301 respondents only two had adverse reactions. This would be an incidence of less than one percent. The adverse reactions were application into the eye of a teenaged girl, causing watering and photophobia and application on the shin of a teenaged boy, causing rash. However in the second instance there is no way to know if the rash was due to deet or due to an allergen like poison ivy. 


\section{CHAPTER FIVE}

\section{CONCLUSIONS AND RECOMMENDATIONS}

Out of a total of 316 families/groups, 301 were found to be using insect repellents which forms an overwhelming $95 \%$ of the people surveyed. This may have been because of the location of the survey, that is, campgrounds. Male care givers were found to be less careful in their approach towards using the insect repellent on faces and palms of children.

In agreement with the first hypothesis, most subjects in this study chose a deet product, considered to be the most effective repellent of those available (Fradin \& Day 2000; Veltri, Osimitz, Bradford, \& Page, 1994). Most other products used in the study are registered with the EPA as insect repellents, but around $2 \%$ of subjects used Avon Skin-So-Soft, a skin moisturizer with no labeled insect repellency claim (not to be confused with Avon's other Skin-So-Soft products containing registered repellents). Interestingly, of the 41 subjects choosing non-deet repellent sprays, aerosols, towelettes, or lotions, $73.1 \%$ applied the product only once, although complete protection time for these products has been estimated at 1.5 hours at most (Fradin $\&$ Day 2000). It is possible, but not likely given the outdoor nature of the activities, that these children needed protection only for short periods of time. Of two cases using citronellacontaining wristbands, one child kept the wristband on for 18 hours, and the other for 24 hours.

From the data provided by subjects regarding the second hypothesis, it is concluded that at least $31 \%$, but no more than $65 \%$, failed to follow label directions. This is because $31 \%$ of parents volunteered that they did not follow label directions. But a larger number were found to follow practices of application which were in violation of label directions. Hence the finding that 
at least $31 \%$ of the subjects; maybe more may actually have failed to follow label directions.

For use on children, health authorities currently recommend products containing $10 \%$ or less deet (Health Canada, 2003; Lowe, 2000; EPA, 1998). Of those parents who used deet on their children in this study, just over half $(53.8 \%)$ chose products containing more than $10 \%$ deet. The finding of no association between deet concentration and age of child treated indicates that most parents purchase a single formulation and use it on the entire family. One subject chose a low concentration deet product for daytime use and a higher concentration for evening. In this study, only one child under six months was treated with a repellent. The father treated the boy, aged three months, with a $21.85 \%$ aerosol formulation of deet; application was made to the child's arms, legs, and feet.

No child under the age of six applied repellent to him/herself in this study, and none of the children applying repellent to their own bodies treated the face directly. Most parents applied the repellents correctly, but a small percentage (10.5\%) treated the face directly. Direct treatment of the face with aerosols or sprays can directly contaminate the eyes and mouth.

Twenty-one percent of subjects using deet applied it more than once on the same day without bathing, swimming, or otherwise washing it off between applications. Some re-treatment may have been necessary in these cases to maintain good efficacy. Fradin \& Day (2000) estimated a mean complete protection time for formulations containing $4.75 \%$ deet to be approximately an hour and a half, whereas a $23.8 \%$ deet formulation gave complete protection for five hours. A few subjects in this study applied deet as frequently as every half hour. Over half of the children in the study did not wash off the repellent before going to bed, regardless of the concentration of deet in the product applied. This practice could lead to contamination of 
bedclothes, creating a constant source of exposure, especially if campers remained for several days and used repellents repeatedly. Over a third of subjects treated the child's clothes as well as the skin, which may be unnecessary.

While the results of this study could reasonably be generalized to use of insect repellents in other campgrounds, the use pattern might be different for use of repellents in everyday situations such as insect protection in one's own yard. In particular, daily bathing may be a more common practice in the home environment as opposed to a campground, where bathing is somewhat less convenient. However, when asked if the patterns of use reported for the last day of use in the campground were representative of their "usual" use of repellents on their children, more than $90 \%$ of the subjects indicated that the pattern was representative. Maryland experienced a very hot summer in 2002 and few of the children in the study wore clothing over treated areas of their bodies, but under cooler conditions, long-sleeved clothing and long pants might be worn after using a repellent earlier in the day.

Factors leading to either more or less frequent use of repellents in everyday situations would include pest pressure in the area, concern about diseases locally transmitted by insects, and other measures taken to reduce mosquito populations in the area (community-wide spray programs, reduction of mosquito habitat, etc.). Beginning the first week of August 2002, news media began to widely report cases of WNV in Maryland. Only 4.6\% of those surveyed prior to August $1^{\text {st }}$ planned to increase use of repellents, whereas $13.9 \%$ of those surveyed after August $1^{\text {st }}$ planned to increase use of repellents. The third hypothesis was negated and significant adverse reactions were not noted.

Minimization of chemical exposure, especially to children, is always desirable. This 
study provides documentation of children's exposure to repellents and identifies practices leading to undesirable exposure. While the study found a high rate of compliance with some of the recommended practices for application, other practices reported were of concern. Most parents chose a low concentration of deet, avoided applying products directly to children's faces, and limited the number of times per day the child was treated without washing or otherwise removing the product between applications. However, almost a third of subjects reported not reading or following label directions, some applied deet directly onto their children's faces, and over half of the children did not wash the repellent off before going to bed. In one instance, an infant was treated with an extremely high concentration of deet.

Considering that somewhere between $31 \%$ and $65 \%$ of the subjects did not follow directions on the product label, it is evident that labeling alone is not sufficient to ensure proper use of repellents. Sudakin \& Trevathan (2003) recently called for toxicologists and poison control centers to play a role in "increasing public awareness of the importance of complying with label instructions" of deet products. Pesticide safety educators and Cooperative Extension personnel, historically involved in developing and implementing pesticide risk minimization programs for professional pesticide applicators, should also work to increase the public's adoption of safer practices. With repellent use likely to increase in areas of the country experiencing West Nile Virus and Lyme disease outbreaks, it would be prudent to increase efforts to educate parents about recommended procedures for use of repellents on children.

Educational campaigns should focus on the use of reduced-concentration products, avoiding treatment of palms or direct treatment of the face, refraining from additional applications unless needed, and washing product off when the child returns indoors. In 
designing educational outreach programs and materials, it may be instructive for educators to understand the factors that contribute to parents' choice of products, as identified in this study. Particular consideration should be given to reaching fathers, as they were more likely than mothers to disregard (or be unaware of) directions to avoid treating face and hands directly.

The fact that significant acute adverse reactions were not found possibly indicates that even though the label directions are not being followed, the regulatory agency (EPA) has given a significantly large margin for error on the part of parents/caregivers. This may explain the fact that even with incorrect application; many adverse effects were not noticed. Another reason may be that the study relied on the opinion of parents as to whether an adverse reaction was there or not and the children were not physically examined. Had they been so examined, more adverse reactions may have been noticed. However, the study was not designed for this. So also, the study was not designed to detect chronic adverse reactions, if any.

\section{Future Research:}

1. This study was a self-report study, and to fully understand the potential of deet to cause acute adverse reactions a study may be designed, involving physical examination of the children at the campgrounds after deet application. This may help document cases of deet toxicity (eg: rashes) unnoticed by parents.

2. Human studies involving deet application for variable periods in order to observe for any possible adverse effects.

3. Long term follow up studies of people who use deet frequently (eg: campground operators) may be conducted to document possible long term sequels of deet use, if any. 
4. Future studies may need to address risk perceptions among parents to deet (Parents may not perceive deet as harmful and that may be the cause of improper application of deet. Future studies may need to address this). 


\section{Appendix A}

\section{MOSQUITO/TICK REPELLENT SURVEY}

NOTE: Instructions in italics are for the researcher. Instructions in bold are to be read to the study participant. Instructions underlined are to be emphasized.

Name of campground:

Date:

Researcher:

1. Are mosquito or tick repellents used on your child/children at least occasionally? no yes

1.a. If no, is it because they have not been needed, or some other reason?

2. How many days have you been at this campground? days

3. During this campground visit, on how many days have insect repellents been used on your children? days

4. What are the age and sex of the children who use insect repellents?

Child \#1: age gender

Child \#2: age ___ gender

Child \#3: age __ gender

Child \#4: age __ gender 
In the next series of questions, please tell me about the most recent day (not counting today) on which your child used an insect repellent applied to the skin. If there is more than one child who uses repellents, please tell me about the repellent(s) used on the youngest child.

4. During this camping trip, what was the most recent day on which your child used a repellent on the skin?

date

6. Was the product a repellent only, or a combination repellent / sunscreen? repellent only combination repellent/sunscreen

6a. If a combination product, what was the primary reason for using the product? pest repellency sun protection both

7. Who applied the repellent to the child?

mother father other primary care giver child

8. Who is answering this survey? If the person identified on first query is not the respondent, ask if you can speak to that person. mother father other primary care giver child

Note to researcher: If a child is to answer the questions, be sure to have the parent sign the assent portion of the form and to have the child sign the assent form. 
9. Now please tell me about the product applied on the most recent day to your youngest child's skin. If the product you used is available, may I see it? Enter information requested below.

If product is not available, ask the following question and record name and active ingredient below: Please look at the photographs and tell me which product you used.

If respondent does not recognize any product from the photos, ask the following question and record name and active ingredient below: Please tell me the name, active ingredient(s), and formulation (liquid, aerosol, pump spray, stick, etc.) of the product you used.

Enter name of product:

Enter EPA registration number:

Enter type of formulation:

Enter active ingredient(s) and concentration(s):

Check appropriate choice indicating how product information was determined:

product shown to researcher

product identified from photos

parent recalled name and concentration information

parent was unable to supply this information

9a. If the product is not available for the researcher to see, ask if you may visit the campsite later to see the product. Record the campsite number:

Upon subsequent visit to campsite, confirm or correct all information collected for question \#9. Remember to change the choice indicating how determined.

10. Have you switched to this brand of repellent from other repellents because of dissatisfaction with a repellent you used previously?

no yes 
10a. If yes, was it because of efficacy _ reaction

10b. If it was because of a reaction, what were the symptom(s)?

11. On the most recent day a repellent was applied to your child's skin, how many times was the repellent applied to the child? times/day

11a. If the repellent was applied more than once on the same day, how much time passed between applications? hours

11b. If the repellent was applied more than once on the same day, what was the reason for repeated application(s)? product had been removed by washing or swimming perceived need for more pest repellency pesticide was not effective enough product was a combination repellent/sunscreen, and more sun protection was needed

12. At what time(s) of day was the repellent applied?

13. What was the main target pest for which you used this repellent? mosquitoes ticks biting flies chiggers 
14. Do you think this product was an effective pest repellent? no __ yes __ don't know

15. Have you increased (or do you expect to increase) use of insect repellents on your children due to concern about

West Nile Virus (transmitted by mosquitoes)

Lyme Disease (transmitted by ticks)

other reasons:

have not increased use / do not plan to increase use

16. To what parts of the body was the repellent applied? (Let the parent self-identify the parts first, then follow up and ask about any parts not mentioned by the parent.)

_ face

neck

ears

scalp

upper arms (shoulder to elbow)

lower arms (elbow to wrist) back of hands palms of hands trunk (chest, back, stomach) thighs/ upper legs shins/calves/lower legs ankles feet

16a. If applied to child's face, how was the product applied? applied to parent's hands, then to child's face applied to child's hands, then to face applied directly to child's face 
17. What clothes did the child wear immediately after application of the repellent? (Let the parent self-identify the clothing first, then follow up and ask about any clothing not mentioned by the parent.)

sleeveless or short sleeved top

long sleeved shirt

shorts/skirt

long pants

sweaters/sweatshirt/jacket

bathing suit sandals socks sneakers/shoes hat

other:

18. Did the child shower, bathe, or swim on that same day after the insect repellent was used?

bathed showered swam none of the above

18a. If yes, at what time of day?

19. Was a product applied to the child's clothing as well as on the skin? did not use a product on the clothing used same product (listed above) used a different pesticide on clothing

19a. If a different product, what were the name active ingredient(s), and concentration(s)?

20. Was a separate sunscreen product used on this child on the same day as the repellent? no yes

20a. If yes, how much time elapsed between application of the sunscreen and application of the repellent? 
20b. If yes, did the child wash off the sunscreen or repellent before applying the other product?

no _ yes

21. How did you decide what insect repellent to use, how often to apply it, where to apply it, etc?

22. Have you used this product before on your child, a different product, or none? never used an insect repellent on this child before used same product previously used a different product

22a. If a different product, what were the name, active ingredient(s), and concentration?

23. How frequently do you use insect repellents on your child when you are not camping? 
24. Thinking about how you usually have used insect repellents on your child, would you say that the use pattern is similar to this most recent time, or do you usually use the repellent somewhat differently with respect to the following: Researcher may need to remind the respondent of previous answers.

product : Do you usually use a different repellent on your child? person who applies: Does a different person usually apply repellent to the child?

If yes, who? areas of the body: Is the repellent usually applied to other parts of the body?

If yes, to what parts?

clothing worn after application: Does the child usually wear different clothing immediately after a repellent is applied?

If yes, what clothing is usually worn after the application?

washing after a repellent is used: Does the child usually bathe, shower, or wash within 24 hours of when a repellent is applied?

If yes, how long after a repellent is applied to the skin does your child usually wash it off? hours after application

25. Does your child suffer from any of the following diseases or conditions? allergies asthma skin diseases any other chronic diseases (diabetes, epilepsy, etc) none

26. Over the past 6 months, what was the general health status of your child? excellent good fair poor 
27. Is your child on any medications now?

no yes

27a. If yes, please tell me which one(s):

27b. How long has the child been on the medication(s)?

med \#1: days

weeks
weeks

months

years

med \#2:

days

med \#3:

days

weeks

months

years

months

years

med \#4:

days

mans

months

years

28. Within one day of using the repellent the last time, did your child have any of the following symptoms? Researcher, circle the symptom noted.

headache dizziness

eye irritation or itching skin irritation, rash, itching, burning sensation, hives asthma attack shortness of breath (not asthma) other respiratory irritation (sore throat, etc.)

GI symptoms(nausea, stomach cramps, vomiting, diarrhea, etc.) behavioral changes (confusion, irritability, depression, etc.) other unusual symptoms: 
28a. If symptoms occurred within a day of use of the repellent, was the child exposed during that time period (one day after application of the repellent) to any sources that normally trigger the same symptoms in this child? no _ yes

29. Are pesticides used inside your home?

on houseplants tcontrol insects, mites, plant diseases, etc.

on surfaces to control crawling pests such as cockroaches, ants, spiders, crickets, etc. on carpets, pet bedding, etc. to control fleas other

30. Are pesticides used outside your home (in your yard or a common area)?

in your flower garden to control insects, weeds, or other pests

on your vegetables or fruits to control insects, weeds, or other pests

on your lawn to control insects, weeds, or other pests other

31. Do you use flea control products on any pets?

no flea control products used fleas collar spray or dust applied to pet liquid applied to pet

Thank you very much for participating in this survey. 


\title{
Appendix B
}

Letter to Campground manager

\author{
Mr. (Name), \\ (Park address) \\ Dear Mr. (Name),
}

I am Dr Kalapurakkal Sunil Menon, graduate student at the University of Maryland. The University of Maryland Pesticide Education and Assessment program is conducting a study on the use of tick and mosquito repellents in Maryland, entitled, "TOPICAL APPLICATION OF PESTICIDES TO CHILDREN: EXPOSURE PROFILE AND POSSIBLE ADVERSE EFFECTS."

As requested by you, I am sending the twenty fliers to you as well as all the other camp managers. I hope you have received the use agreement form I had signed and sent. Please do mail me once all documents are fine, or if I need do anything else. I thank you very much for the interest and cooperation you had extended to my project.

The study will commence by the third week of May 2002, and I shall contact you at least one week prior to coming to the park.

I thank you once again for the cooperation extended to me in this regard.

Thanking you,

Sincerely,

Dr. K Sunil Menon. 


\section{Appendix C}

\section{FLYER}

\section{Use of Topically-Applied Repellents on Children}

The University of Maryland Pesticide Education and Assessment program is conducting a study on the use of tick and mosquito repellents in Maryland. We are interested in which treatments were applied, how often they were used, how effective you find them, and whether you have experienced any problems with these products. The information we collect will be used to develop educational materials to help people use these repellents safely and effectively.

We are seeking parents or child care givers who would be willing to answer a brief set of questions - the questionnaire should only take a few minutes. All information will remain confidential; we are not requesting individuals' names, addresses or other identifying information. If you agree to participate in the survey, you may refuse to answer any question(s) you find objectionable, and you may stop at any time.

This research project is being funded from registration fees and other income from workshops and educational materials developed by the University of Maryland Pesticide Education and Assessment Program (PEAP). The results of the survey will be posted on the University of Maryland PEAP website at http://pesticide.umd.edu after it is accepted for publication. If you are interested in learning the results, we anticipate that the study will be posted by Spring 2004. Information about proper use of pesticides, as well as links to helpful sites, may also be found on the PEAP website. 


\section{Appendix D}

\section{MOSQUITO/TICK REPELLENT SURVEY WITH ANSWERS}

NOTE: Instructions in italics are for the researcher. Instructions in bold are to be read to the study participant. Instructions underlined are to be emphasized.

Name of campground:

Date:

Researcher:

1. Are mosquito or tick repellents used on your child/children at least occasionally?

$$
15 \text { no } \quad 301 \text { yes }
$$

1.a. If no, is it because they have not been needed, or some other reason?

The answers were: Perceived inefficiency of deet (five subjects), fear of toxicity (four subjects), "mosquitoes do not bite us," (two subjects), "Have never wanted to use any," (three subjects) and no reason was given by one person.

2. How many days have you been at this campground? (Please refer to results section)

3. During this campground visit, on how many days have insect repellents been used on your children? (Please refer to results section)

4. What are the ageand sex of the children who use insect repellents? (mentioned in results section)

Child \#1:__ age ___ gender (Please refer to results section) 
In the next series of questions, please tell me about the most recent day (not counting today) on which your child used an insect repellent applied to the skin. If there is more than one child who uses repellents, please tell me about the repellent(s) used on the youngest child.

5. During this camping trip, what was the most recent day on which your child used a repellent on the skin? (Please refer to results section)

date

Answers recorded for Qs 6 (except 6a) to 9 are in the results section. Question 9a was never used.

6. Was the product a repellent only, or a combination repellent / sunscreen? repellent only combination repellent/sunscreen

6a. If a combination product, what was the primary reason for using the product? 1: pest repellency $\quad$ 8: sun protection $\quad 22$ both

7. Who applied the repellent to the child? mother father other primary care giver child

8. Who is answering this survey? If the person identified on first query is not the respondent, ask if you can speak to that person. mother father other primary care giver child

Note to researcher: If a child is to answer the questions, be sure to have the parent sign the assent portion of the form and to have the child sign the assent form. 
9. Now please tell me about the product applied on the most recent day to your youngest child's skin. If the product you used is available, may I see it? Enter information requested below.

If product is not available, ask the following question and record name and active ingredient below: Please look at the photographs and tell me which product you used.

If respondent does not recognize any product from the photos, ask the following question and record name and active ingredient below: Please tell me the name, active ingredient(s), and formulation (liquid, aerosol, pump spray, stick, etc.) of the product you used.

Enter name of product:

Enter EPA registration number:

Enter type of formulation:

Enter active ingredient(s) and concentration(s):

Check appropriate choice indicating how product information was determined:

product shown to researcher

product identified from photos

parent recalled name and concentration information

parent was unable to supply this information

9a. If the product is not available for the researcher to see, ask if you may visit the campsite later to see the product. Record the campsite number:

Upon subsequent visit to campsite, confirm or correct all information collected for question \#9. Remember to change the choice indicating how determined.

10. Have you switched to this brand of repellent from other repellents because of dissatisfaction with a repellent you used previously?

13: yes 0 : No 


\section{0a. If yes, was it because of}

9: efficacy ; 0: reaction; 2: wanted lower deet concentration; one: wanted to use a sunscreen and deet combination and one person had no reason.

10b. If it was because of a reaction, what were the $\underline{\operatorname{symptom}(\mathrm{s})}$ ?

11. On the most recent day a repellent was applied to your child's skin, how many times was the repellent applied to the child? (Please refer to results section) times/day

11a. If the repellent was applied more than once on the same day, how much time passed between applications? hours

(Please refer to results section)

11b. If the repellent was applied more than once on the same day, what was the reason for repeated application(s)? product had been removed by washing or swimming perceived need for more pest repellency pesticide was not effective enough product was a combination repellent/sunscreen, and more sun protection was needed

(Please refer to results section)

12. At what time(s) of day was the repellent applied?

(The answers to questions 11 and 12 were used to calculate repellent contact hours; reported in the results section)

13. What was the main target pest for which you used this repellent?

226: mosquitoes 37: ticks 28: biting flies 8: chiggers

1 each: Gnats and Horse flies. 
14. Do you think this product was an effective pest repellent? no yes don't know

(Please refer to results section)

15. Have you increased (or do you expect to increase) use of insect repellents on your children due to concern about

West Nile Virus (transmitted by mosquitoes)

Lyme Disease (transmitted by ticks)

other reasons:

have not increased use / do not plan to increase use

(Please refer to results section)

16. To what parts of the body was the repellent applied? (Let the parent self-identify the parts first, then follow up and ask about any parts not mentioned by the parent.)

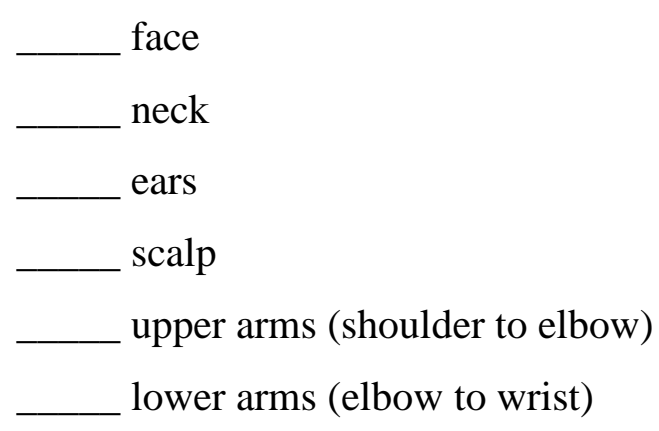

16a. If applied to child's face, how was the product applied? applied to parent's hands, then to child's face applied to child's hands, then to face applied directly to child's face

(Please refer to results section) 
17. What clothes did the child wear immediately after application of the repellent? (Let the parent self-identify the clothing first, then follow up and ask about any clothing not mentioned by the parent.)

260: sleeveless or short sleeved top

72: sandals

8 : long sleeved shirt

45: socks

256: shorts/skirt

45: sneakers/shoes

19: long pants

16: hat

2: sweaters/sweatshirt/jacket

1: Nightgown

32: bathing suit

18. Did the child shower, bathe, or swim on that same day after the insect repellent was used?

bathed showered swam none of the above

228 people bathed, showered or swam after the insect repellent was applied. No distinction was done while collecting data. The remaining 73 people did not wash off the repellent in any way. Washing off has been defined in definition section of chapter one.

18a. If yes, at what time of day?

(This was unfortunately not properly recorded and so meaningful inferences cannot be drawn)

19. Was a product applied to the child's clothing as well as on the skin? (Please refer to results section) did not use a product on the clothing used same product (listed above) used a different pesticide on clothing

19a. If a different product, what were the name :None active ingredient(s), and concentration(s)? 
20. Was a separate sunscreen product used on this child on the same day as the repellent? 293: no 8: yes

20a. If yes, how much time elapsed between application of the sunscreen and application of the repellent? Average 3.7 hours

20b. If yes, did the child wash off the sunscreen or repellent before applying the other product?

6: no 2 : yes

(Answers for questions 21 to 22: Please refer to results section)

21. How did you decide what insect repellent to use, how often to apply it, where to apply it, etc?

22. Have you used this product before on your child, a different product, or none? never used an insect repellent on this child before used same product previously used a different product

22a. If a different product, what were the name, active ingredient(s), and concentration?

23. How frequently do you use insect repellents on your child when you are not camping?

(Data was not recorded well, and so meaningful inferences cannot be drawn) 
24. Thinking about how you usually have used insect repellents on your child, would you say that the use pattern is similar to this most recent time, or do you usually use the repellent somewhat differently with respect to the following: Researcher may need to remind the respondent of previous answers.

product : Do you usually use a different repellent on your child? person who applies: Does a different person usually apply repellent to the child?

If yes, who? areas of the body: Is the repellent usually applied to other parts of the body?

If yes, to what parts?

clothing worn after application: Does the child usually wear different clothing immediately after a repellent is applied?

If yes, what clothing is usually worn after the application?

washing after a repellent is used: Does the child usually bathe, shower, or wash within 24 hours of when a repellent is applied?

If yes, how long after a repellent is applied to the skin does your child usually wash it off? hours after application

(Data was not collected properly and so meaningful inferences could not be drawn. However, most of the subjects opined that their use patterns at home paralleled the use patterns at campground)

25. Does your child suffer from any of the following diseases or conditions?

8: allergies

6: asthma

11: skin diseases

Chronic diseases: Diabetes: 1; Ulcerative colitis: 1; Epilepsy: 1.

279: None

26. Over the past 6 months, what was the general health status of your child?

79: excellent 218: good 4: fair 0: poor 


\section{Is your child on any medications now?}

294: no 7: yes

27a.If yes, please tell me which one(s): The medications were: Over the counter analgesics, topical ointments, sulphasalazine and steroids (for ulcerative colitis), sodium valproate (for epilepsy), insulin (for diabetes), beclomethasone and salbutamol inhaler (for asthma), antihistamines and antifungal ointment.

27b. How long has the child been on the medication(s)?

For the chronic conditions listed above, the medications were on for years but for acute conditions, only a few days.

28. Within one day of using the repellent the last time, did your child have any of the following symptoms? Researcher, circle the symptom noted.

0 : headache

0 : dizziness

1: eye irritation or itching

1: skin irritation, rash, itching, burning sensation, hives

0 : asthma attack

0 : shortness of breath (not asthma)

0 : other respiratory irritation (sore throat, etc.)

0: GI symptoms(nausea, stomach cramps, vomiting, diarrhea, etc.)

0: behavioral changes (confusion, irritability, depression, etc.)

0 : other unusual symptoms

28a. If symptoms occurred within a day of use of the repellent, was the child exposed during that time period (one day after application of the repellent) to any sources that normally trigger the same symptoms in this child?

1: no $\quad 1$ : yes 


\section{Are pesticides used inside your home?}

on houseplants to control insects, mites, plant diseases, etc. on surfaces to control crawling pests such as cockroaches, ants, spiders, crickets, etc. on carpets, pet bedding, etc. to control fleas other

The answers to these questions were recorded as Yes, No or Don't know and not as per above. One hundred and eight subjects responded that they do use pesticides inside their home while 192 responded negatively. One person was unsure.

\section{Are pesticides used outside your home (in your yard or a common area)?}

__ in your flower garden to control insects, weeds, or other pests

_

__ on your lawn to control insects, weeds, or other pests

__ other

The answers to these questions were recorded as Yes, No or Don't know and not as per above. Eighty seven subjects responded that they do use pesticides outside their home while 212 responded negatively. Two people were unsure.

\section{Do you use flea control products on any pets?}

203: No flea control products used

24: flea collar

1: spray or dust applied to pet

69: liquid applied to pet

2: Shampoo

1: Pills

1: Flea bath 


\section{Appendix E}

\section{Informed Consent and/or Permission Form}

\section{Project title: $\quad$ Topical Application of Insecticides to Children}

Purpose: The University of Maryland Pesticide Education and Assessment program is conducting a study on the use of insecticides applied to children in Maryland. The researchers are interested in which treatments were applied, how often they were used, how effective I have found them, and whether my family has experienced any problems with these products.

Procedures: The procedure involves answering a questionnaire prepared by the researchers.

Confidentiality: All information collected in the study is confidential. No personally identifying information is being requested, and the answers I provide will be grouped with data others provide for reporting and presentation. This consent form will be maintained in a separate file from the questionnaire.

Risks: There are no foreseeable risks associated with participating in this study.

Benefits, freedom to withdraw and to ask questions: I understand that the experiment is not designed to help me personally, but that the investigators expect to use the results to prepare educational materials to help parents understand how to use these products in the safest manner possible. I understand that I am free to ask questions or to withdraw from participation at any time without penalty.

Consent: I state that I am over 18 years of age and wish to participate in the research project being conducted by Dr. Amy Brown, Associate Professor in the Department of Entomology at the University of Maryland, College Park, MD 20742.

(Printed name of participant)

(Signature of participant) (Date)

\section{AND/OR}

Permission: I state that I am over 18 years of age and wish to allow my minor child (under the age of 18) to participate in the research project being conducted by Dr. Amy Brown, Associate Professor in the Department of Entomology at the University of Maryland, College Park, MD 20742 .

(Printed name of participant)

(Signature of participant) (Date) 


\section{Appendix $F$}

\section{Assent Form}

\section{Project title: Topical Application of Insecticides to Children}

Purpose: The University of Maryland Pesticide Education and Assessment program is conducting a study on the use of insecticides applied to children in Maryland. The researchers are interested in which treatments were applied, how often they were used, how effective I have found them, and whether my family has experienced any problems with these products.

Procedures: The procedure involves answering questions read by the researcher.

Participation should take less than 10 minutes.

Confidentiality: All information collected in the study is confidential. No personally identifying information is being requested, and the answers I provide will be grouped with data others provide for reporting and presentation. This consent form will be maintained in a separate file from the questionnaire.

Risks: There are no foreseeable risks associated with participating in this study.

Benefits, freedom to withdraw and to ask questions: I understand that the experiment is not designed to help me personally, but that the investigators expect to use the results to prepare educational materials to help parents understand how to use these products in the safest manner possible. I understand that I am free to ask questions or to withdraw from participation at any time without penalty.

Assent: I state that I am under 18 years of age and wish to participate in the research project being conducted by Dr. Amy Brown, Associate Professor in the Department of Entomology at the University of Maryland, College Park, MD 20742. My parent or guardian has signed a permission form agreeing to allow me to participate in this study. 


\section{REFERENCES}

American Academy of Pediatrics Committee on Infectious Diseases. (2000). Prevention of Lyme disease. Pediatrics, 105 (1), 142-147.

Bell J.W., Veltri J.C.,\& Page B.C. (2002). Human exposures to N,N-diethyl-m-toluamide insect repellents reported to the American Association of Poison Control Centers 1993-1997. International Journal of Toxicology, 21(5), 341-52.

Briassoulis G., Narlioglou M.,\& Hatzis T. (2001). Toxic encephalopathy associated with use of DEET insect repellents: a case analysis of its toxicity in children. Human Experiments and Toxicology, 20 (1), 8-14.

Brown, A.E. (1999). Understanding pesticides, Maryland Cooperative Extension, University of Maryland, College Park, Pesticide information leaflet No.27, Feb 1999.

Craigmill A. (1998). Safer use of deet was goal of new labeling. Environmental Toxicology Newsletter, 18:1.

Edwards D.L., \& Johnson C.E. (1987). Insect repellent induced toxic encephalopathy in a child. Clinical Pharmacology (6), 496-8.

Fradin M.S.,\& Day J.F. (2000). Comparative efficacy of insect repellents against mosquito bites. New England Journal of Medicine, 347(1),13-8. 
Hampers L.C., Oker E., \& Leikkin J.B. (1999). Topical use of deet insect repellent as a cause of severe encephalopathy in a healthy adult male. Academic Emergency Medicine, 6(12), 1295-7.

Hayes W.J. Jr.,\& Laws E.R. Jr., eds. (1991).Handbook of Pesticide Toxicology. Vol 3. Classes of Pesticides. New York:Academic Press Inc. 1503.

Health Canada. (2003).Safety Tips on Using Personal Insect Repellents. Retrieved on $7^{\text {th }}$ June 2003, from http://www.hc_sc.gc.ca/pmra_arla/english/pdf/pnotes/deet_e.pdf.

Lipscomb J.W., Kramer J.E.,\& Lefkin J.B. (1992). Seizure following brief exposure to the insect repellent N,N-diethyl-m-toluamide. Annals of Emergency Medicine, 21(3), 315-7.

Lowe, C. (Ed.) (2000). Information for Clinicians: Common Insect Repellents and Mosquito Control Products. City Health Information, The New York City Department of Health, New York, NY. 19(s.1), 1-2.

Murphy M.E., Montemarano A.D., Debboun M., \& Gupta R. (1994): The effect of sunscreen on the efficacy of the insect repellent. Journal of the American Academy of Dermatology 2000, 43(2), 219-222.

New York Department of Environmental Conservation. (1994). Forum: bug sprays worse than the bites? Environmental Health Perspectives 102:910. 
Osimitz T.G., \& Murphy J.V. (1997). Neurologic effects associated with use of the insect repellent N, N Diethyl-m-toluamide(DEET). Journal of Toxicology and Clinical Toxicology, $35(5), 435-41$.

Petrucci N, \& Sardini S. (2000). Severe neurotoxic reaction associated with oral ingestion of low dose diethyltoluamide containing insect repellent in a child. Pediatric Emergency Care. Oct; 16(5), 341-2.

Qiu H, Jun H.W.,\& McCall J.W. (1998). Pharmacokinetics, formulation, and safety of insect repellent N,N-diethyl-3-methylbenzenamide (deet): a review. Journal of American Mosquito Control Association 14(1), 12-27.

Reigart J.R., \& Roberts J.R. (1999).Recognition and Management of Pesticide Poisonings, $5^{\text {th }} e d$. EPA Office of Prevention, Pesticides, and Toxic Substances.

Riviere J.E., Baynes R.E., Brooks J.D., Yeatts J.L.,\& Monteiro-Riviere N.A. (2003). Percutaneous absorption of topical N, N-diethyl-m-toluamide (DEET): effects of exposure variables and coadministered toxicants. Journal of Toxicology and Environmental Health $66(2), 133-51$.

Roland E.H.,Jan J .E.,\& Rigg J.M. (1985). Toxic encephalopathy in a child after brief exposure to insect repellents. Canadian Medical Association Journal 132(2), 155-6.

Smallwood A.W., DeBord K.E.,\& Lowry L.K. (1992). N, N-diethyl-m-toluamide (m-deet): 
analysis of an insect repellent in human urine and serum by high-performance liquid chromatography. Journal of Analytical Toxicology 16,10- 3.

Smith C.N., Gilbert I.H., Gouck H.K., Bouman M.C., Acree Jr F., \& Schmidt C.H. (1963). Factors affecting the protection period of mosquito repellents. USDA Technical Bulletin No 1285.

Spencer T.S., Hill J.A., Feldmann R.J.,\& Maibach H.I. (1979). Evaporation of diethyltoluamide from human skin in vivo and in vitro. Journal of Investigative Dermatology $72,317-9$.

Sudakin D.L., \& Trevathan W.R. (2003). DEET: A review and update of safety and risk in the general population. Journal of Toxicology Clinical Toxicology 41(6), 831-9.

EPA.(1998). Reregistration of the Insect Repellent DEET. Retrieved on $7^{\text {th }}$ June 2003 from http://www.epa.gov/pesticides/factsheets/chemicals/deet.htm.

Veltri J.C., Osimitz T.G., Bradford D.C., \& Page B.C. (1994). Retrospective analysis of calls to poison control centers resulting from exposure to the insect repellent N,N-diethyl-mtoluamide (DEET) from 1985-1989. Journal of Toxicology Clinical Toxicology 32(1), 1-16. 